\title{
Environmental and financial performance of mechanical recycling of carbon fibre reinforced polymers and comparison with conventional disposal routes
}

\author{
Xiang $\mathrm{Li}^{1,2}$ Ruibin $\mathrm{Bai}^{1}$, Jon McKechnie ${ }^{2 *}$ \\ ${ }^{1}$ Department of Science and Engineering, University of Nottingham, \\ Taikang East Road No.199, Ningbo, China \\ ${ }^{2}$ Department of Mechanical, Materials \& Manufacturing Engineering, University of \\ Nottingham, Nottingham NG7 2RD, UK \\ Email: Xiang.Li@nottingham.edu.cn \\ Email: Jon.Mckechnie@nottingham.ac.uk
}

\begin{abstract}
Recovering value from carbon fibre reinforced polymers waste can help to address the high cost and environmental burden of producing carbon fibres, but there is limited understanding of the cost and environmental implications of potential recycling technologies. The objective of this study is to assess the environmental and financial viability of mechanical recycling of carbon fibre composite waste. Life cycle costing and environmental assessment models are developed to quantify the financial and environmental impacts of alternative composite waste treatment routes, comparing landfilling, incineration with energy recovery, and mechanical recycling in a UK context. Current Landfill Tax results in incineration becoming the lowest cost composite waste treatment option; however, incineration is associated with high greenhouse gas emissions as carbon released from composite waste during combustion exceeds $\mathrm{CO}_{2}$ emissions savings from displacing UK electricity and/or heat generation, resulting in a net greenhouse gas emissions source. Mechanical recycling and fibre reuse to displace virgin glass fibre can provide the greatest greenhouse gas emissions reductions of the treatment routes considered ( $-378 \mathrm{~kg} \mathrm{CO}_{2} \mathrm{eq} . / \mathrm{t}$ composite waste), provided residual recyclates are landfilled rather than incinerated. However, this pathway is found to be unfeasible due to its high cost, which exceeds $£ 2,500 / \mathrm{t}$ composite waste $(\$ 3,750 / \mathrm{t}$ composite waste). The financial performance of mechanical recycling is impaired by the high costs of dismantling and recycling processes; low carbon fibre recovery rate; and low value of likely markets. To be viable, carbon fibre recycling processes must achieve near-100\% fibre recover rates and minimise the degradation of fibre mechanical properties to enable higher-value applications (e.g., virgin carbon fibre displacement). Ongoing development of carbon fibre recovery technologies and composite manufacturing techniques using recycled carbon fibres leading to improved material properties is therefore critical to ensuring financial viability and environmental benefit of carbon fibre reinforced polymer recycling.
\end{abstract}

Keywords: life cycle assessment, life cycle cost, composite waste treatment, carbon fibre recycling

\section{INTRODUCTION}

Carbon fibre reinforced polymer (CFRP) is already a common lightweight material in aerospace applications and is expected to be increasingly used in automotive applications into the future. For transport applications, fuel savings can be achieved when CFRP is used in place of heavier materials such as steel and aluminium, with studies reporting energy savings of greater than $5 \mathrm{GJ}$ per $\mathrm{kg}$ of steel displaced in automotive applications (Das, 2011; Duflou et al., 2009). In the past ten years, CF's annual demand worldwide has increased from approximately 16,000 to 72,000 tonnes and is expected to reach 140,000 tonnes/yr by 2020 in estimation (Witten et al., 2014). Correspondingly, CFRP wastes from manufacturing processes and end-of-life products are expected to increase. Virgin carbon 
fibre (vCF) is an energy-intensive and costly material, and therefore recycling of CFRP wastes could recover substantial financial value while contributing to waste mitigation objectives. To ensure that recycling strategies contribute to this aim, it is necessary to understand their environmental impacts and financial viability.

Recycling of CFRP wastes is encouraged by the high cost and energy intensity of vCF production. Manufacture of vCF costs 20-40 £/kg in the UK (Pimenta \& Pinho, 2011) and directly consumes about 183 286 MJ per kg, which is roughly 10 times more energy-intensive than glass fibre production (Howarth et al., 2014) and approximately 14 times more energy-intensive than conventional steel (Das, 2011). Greenhouse gas emissions associated with vCF production have been estimated previously at $31 \mathrm{~kg} \mathrm{CO}_{2}$ eq per $\mathrm{kg}$, which is 10 times more than conventional steel at as $3 \mathrm{~kg}$ $\mathrm{CO}_{2}$ eq per kg production (Das, 2011). Recovering CF from CFRP wastes could help to compensate for these production impacts.

Existing waste mitigation policies further encourage value recovery from CFRP wastes. The landfill tax scheme in the UK is a financial disincentive applied to landfilling to encourage the diversion of wastes to alternative treatment processes by applying a charge to waste entering landfill (EC, 2012). The End of Life Vehicle Directive (EC, 2000) is relevant to automotive applications of CFRPs and mandates material recovery of end of life vehicles with objectives of reducing waste and improving environmental performance when automotive vehicles enter into end of life. A recycling target of $85 \%$ and a total recovery of $95 \%$ (including incineration) are newly initiated from 2015 , allowing only $5 \%$ of a vehicle to be deposited into landfill and no more than $10 \%$ entering energy recovery. Developing viable CFRP recycling and recovery technologies is essential for future lightweight automobiles to comply with this legislation.

While there are numerous drivers supporting the recycling of automotive wastes, common difficulties in cost-effectively recovering non-metal material from automotive components result in a financial and environmental burden associated with such wastes. Currently, non-metal materials in the automotive sector - and particularly plastics - maintain low recycling rates in Europe, with the bulk of this material remaining in automotive shredder residue that is combusted for energy recovered or landfilled (Sakai et al., 2014; Santini et al., 2011). In contrast, metals used in transport applications, such as steel, are easily recovered at high recycling rates (Graedel et al., 2011). Vehicle lightweighting is a driver for increasing utilisation of plastics in future cars and risks impairing vehicle material recycling rates due to financial and technical barriers to recovering post-shredder plastic residues (Passarini et al., 2012) . To increase the plastics recycling rate, labour- and cost-intensive dismantling is required to separate and collect material prior to shredding. Reviewing literatures to date, large scale of plastic components dismantled to recycling is limited by the lack of a viable recycling network and uncertain markets for recovered materials (Chen et al., 2015; Duval \& MacLean, 2007; Shapiro \& Johannessen, 2015). Despite economic constraints, numerous studies have found environmental benefits to be realised from automotive plastic recycling, including reductions in energy consumption, greenhouse gas emissions, and non-renewable resource depletion (Ciacci et al., 2010; Duval \& MacLean, 2007).

It is anticipated that CFRP waste from automobiles would face similar barriers to plastics, while its mixed-material nature may create additional technical and economic barriers to successful material recovery. Material recovery from CFRP wastes is complicated by the cross-linked matrix structure (typically epoxy resin), absence of standard composition, and difficulty characterising waste materials to optimise recovery processes (Pickering, 2006; Witik et al., 2013). A number of CFRP recycling methods have been successfully trialled including mechanical recycling, pyrolysis and fluidised bed processes (Pickering, 2006). However, the uncertain economic viability of recycling processes and availability of markets for recycled material are two key barriers to the implementation of CFRP recycling. Recycled carbon fibres $(\mathrm{rCF})$ from mechanical recycling processes typically exhibit reduced mechanical properties and reduction in fibre length, thereby forcing these materials to lower-value applications than virgin carbon fibres (vCF) (Palmer et al., 2010). More advanced techniques such as 
pyrolysis and fluidised bed, which thermochemically decompose the cross-linked matrix material, can recovery clean and high quality $\mathrm{rCF}$, but are expected to exhibit higher process costs and greater energy intensity than mechanical recycling. Moreover, reuse of $\mathrm{rCF}$ from pyrolysis and fluidised bed is not straightforward due to the fluffy nature of the $\mathrm{rCF}$ and surface properties that can impair binding with polymeric matrix materials (Oliveux et al., 2015; Pimenta \& Pinho, 2011). As a consequence, CFRP may enter conventional waste treatment routes, including landfill and incineration, where minimal value can be recovered.

In order to assess the environmental and financial impact of waste treatment systems, life cycle assessment (LCA) (ISO, 2006) and life cycle cost (LCC) methods (Fabrycky \& Blanchard, 1991) can be applied. LCA and LCC methods have been broadly applied to waste treatment systems, including investigations of end-of-life vehicles (Alonso et al., 2007; Duval \& MacLean, 2007) and a wide range of other post-consumer products including plastics (Simões et al., 2013), home appliances (Kim et al., 2009), and general municipal solid waste management (Zhao et al., 2011). While these studies generally agree that recycling and other reutilisation scenarios can achieve environmental benefits (in terms of energy use, greenhouse gas emissions, resource depletion, etc.), financial viability is very dependent on specific cases and parameters such as total recycling cost and markets/value of recovered materials. Prior studies specific to CFRP waste recycling include an evaluation of the energy consumption associated with mechanical recycling (Howarth et al., 2014). Witik et al. (2013) conducted a life cycle study of a pyrolysis-based CFRP recycling process to assess environmental impacts; while this study lacked accurate data as to the energy requirements of the CFRP recycling process, it expanded on existing LCA studies investigating the production and use phases of CFRP products (Das, 2011; Timmis et al., 2015; Witik et al., 2011) to include CFRP end-of-life. However, to our knowledge no previous study has combined LCA and LCC methods to assess both the financial and environmental impacts of CFRP waste treatment.

This paper develops LCA and LCC models to quantify the financial and environmental (global warming potential, primary energy use, landfill waste generation) impacts of mechanical CFRP waste recycling. We compare mechanical recycling with conventional treatments (landfill, incineration) to address trade-offs between treatment options and assess the potential impacts of current waste treatment regulations in the UK and EU. A case study is conducted considering automotive CFRP waste.

\section{METHODS}

This study assesses the environmental impact and financial performance of waste CFRP treatments when carbon fibre-based composite materials in end of life vehicles are disposed of. We consider three possible end-of-life treatments of waste CFRP materials: landfilling, incineration with energy recovery; and mechanical recycling to recover materials for use as fibre reinforcement and/or filler material. Trade-offs between the alternative treatment routes are assessed in the context of current waste regulations in the UK and EU.

Life cycle inventory (LCI) models are developed to quantify environmental impacts associated with the waste CFRP treatments. The functional unit for the analysis is one tonne waste CFRP entering the waste treatment processes. Global warming potential (GWP), primary energy use, and landfill waste generation are quantified to assess environmental impacts. Global warming potential is reported as carbon dioxide equivalent $\left(\mathrm{CO}_{2}\right.$ eq. $)$ based on 100 year greenhouse gas factors from IPCC 2013 (Stocker et al., 2013). Energy use is reported as primary energy consumption (MJ) and disaggregated between non-renewable and renewable sources. The quantity of waste going to landfill is associated with land use impact and directly links to waste mitigation policies, such as the EU landfill directive to divert landfill waste (Herczeg et al., 2009). Landfill waste generation is quantified as the mass of waste entering landfill $(\mathrm{t})$. 
Figure 1 shows key activities within the system boundary of the study. "Gate to grave" modules are developed for CFRP waste treatment by landfilling and incineration, beginning at the point where end-of-life vehicle has been collected and including waste processing (disassembly, shredding), transport, and waste treatment (landfill, incineration). For recycling, a "gate to gate" approach is taken which includes the production of composite materials from recycled carbon fibres $(\mathrm{rCF})$ and the use and/or disposal of other recyclate materials. The initial production and use phase of the automotive CFRP is identical for all waste treatments and thus excluded from this study. Maintenance and facility construction are also not included in the LCI boundaries. When energy and/or materials are recovered by CFRP waste treatment processes, we employ a system expansion approach to quantify impacts of their reuse and displacement of reference products. Recovered energy from incineration (electricity, heat) is assumed to displace electricity production from the average UK grid mix and heat production from natural gas. Materials recovered as $\mathrm{rCF}$ and powder recyclates are assumed to displace a range of materials in composite manufacture (see Section 2.4). Process-specific data sources are supplemented by LCA databases, e.g., Ecoinvent (Hischier, 2014) to develop full life cycle, spreadsheet-based models. Waste CFRP is assumed to have a CF content of $60 \mathrm{wt} \%$. The polymer matrix (40\%wt) is assumed to be an epoxy resin (diglycidyl ether of bisphenol-A).

Life cycle cost models are developed to calculate the total cost of the waste treatment routes. The goal for this financial analysis is to compare the costs of the waste CFRP treatment routes and evaluate the trade-offs with environmental impacts. The system boundary of LCC is aligned with the LCI model. Regulatory costs, such as the UK's landfill tax, are also considered. Further details on the life cycle cost methods are provided in Section 2.5.

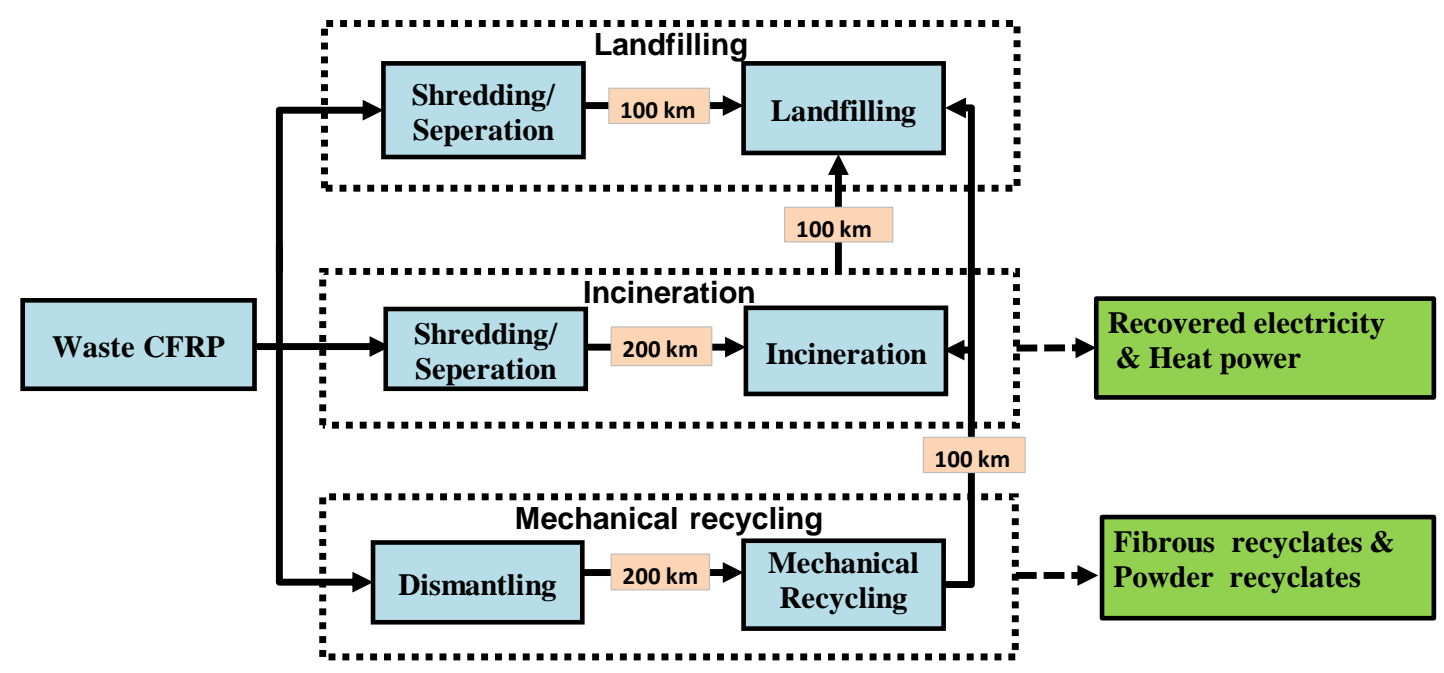

Figure. 1. Model of waste treatments processes: landfilling, incineration and mechanical recycling

\subsection{CFRP waste collection and pre-treatment}

Both the LCI and LCC models begin where end-of-life automotive vehicles have been collected. Prior to undergoing waste treatments processes, CFRP waste components undergo pre-treatment. CRFP destined to landfilling or incineration are shredded with other vehicle components, consuming electricity at $0.09 \mathrm{MJ} / \mathrm{kg}$ (Witik et al., 2011). In contrast, recycling of CFRP waste begins with dismantling to separate CFRP from other materials prior to shredding. The dismantling process is assumed to be manual work with no energy consumption. CFRP wastes are transported to the treatment site by 32 tonne standard dump truck. As we are modelling hypothetical scenarios, we assume transport distances of $100 \mathrm{~km}$ (to landfill) and $200 \mathrm{~km}$ (to incineration or mechanical recycling). Residual waste material arising from the recycling process, which is either landfilled or incinerated, is assumed to be transported additional $100 \mathrm{~km}$ distance from recycling site to landfill site or incineration 
site. Combustion ash generated from incineration processes is assumed to transport 100km distance to landfill.

\subsection{Landfilling}

The disposal of CFRP components in landfill is assumed to occur in a sanitary landfilling site which is built for the final disposal of solid waste. Impacts associated with CFRP landfilling are assessed based the Ecoinvent sanitary landfill dataset (Hischier, 2014). Due to the inert nature of CFRP waste, we assume that no significant environmental impacts (e.g., methane emissions) or costs occur following disposal.

\subsection{Incineration}

Incineration of CFRP wastes enables the recovery of a portion of the embodied energy for useful purpose. Advanced incineration facilities can co-produce heat and electricity to supply local thermal energy demands and to export electricity to the grid. Prior reports have suggested CFRP waste can be mixed at 10\% loading in municipal solid waste (MSW) and used as an energy source (Pickering, 2012).

The potential for energy production from CFRP waste is dependent on its energy content (carbon fibre and polymer matrix) and the efficiency of generating useful energy outputs (heat, electricity). Typical energy content of CFRP waste is approximately $30 \mathrm{MJ} / \mathrm{kg}$ calorific value (Hedlund-Åström, 2005). Based on the CFRP composition assumed here (60\% fibre, $40 \%$ matrix), an energy content of $32 \mathrm{MJ} / \mathrm{kg}$ is calculated (Pickering, 2012). Waste incineration with energy recovery is typically less efficient than that producing heat and electricity from refined fuels; electricity and heat generation efficiencies are assumed to be $13 \%$ and $25 \%$ respectively, giving a total conversion efficiency of $38 \%$ (Hischier, 2014). These efficiency assumptions are justified by other sources, including DEFRA (2013) which cites electricity-only generation efficiencies of $14 \%$ to $27 \%$. We consider a second, "highefficiency" incineration scenario where state-of-the art efficiencies are achieved (25\% electricity generation; 55\% heat generation efficiencies). Higher efficiencies are not considered to be likely, as reported waste incineration boiler efficiencies are limited to $84 \%$ (EC, 2006). Electricity is assumed to displace the average UK generation mix comprised of $36 \%$ coal, $27 \%$ gas, $20 \%$ nuclear, $14.9 \%$ renewables and other sources (MacLeay, 2014). Generated heat is assumed to displace heat production from natural gas combustion, assuming $80 \%$ efficiency. $\mathrm{CO}_{2}$ emissions from incineration process are quantified based on stoichiometric balances, assuming all carbon content of CFRP is oxidised and emitted as $\mathrm{CO}_{2}$. Non- $\mathrm{CO}_{2}$ emissions from combustion are assumed to be negligible. Net greenhouse gas emissions are assessed by taking into account both the direct emissions from CFRP waste combustion and avoided emissions associated with displacing grid electricity and heat power from natural gas. Residual materials following combustion, e.g., ash, account for $8 \%$ of CFRP waste (Hischier, 2014) and is assumed to be disposed of in landfill as described in section 2.2.

\subsection{Mechanical recycling}

Mechanical recycling of CFRP waste involves the size reduction and recovery of fibres and powder recyclates for reuse, which has been reported in several studies (Palmer et al., 2009; Pimenta \& Pinho, 2011). Waste CFRP is firstly cut into 50 to $100 \mathrm{~mm}$ size pieces by shredder and then grinded by hammer mill for further size reduction. Grading procedures using sieves and cyclones separate the recyclates into fibre- and power-rich fractions.

Greenhouse gas emissions and energy use associated with the mechanical recycling process are modelled, including CFRP waste pre-treatment and the production of energy inputs for size reduction and mechanical recycling processes (e.g. electricity generation). CFRP components are assumed to be initially shredded to $50 \mathrm{~mm}$ size before transport to the mechanical recycling facility. Transport distance is assumed to be $200 \mathrm{~km}$ in order to achieve sufficient scale of recycling operations, although this value is very hypothetical given that CFRP mechanical recycling facilities modelled here do not exist in the UK. Energy requirements are dependent on final recyclates size and capacity; data 
employed in this study are for $6 \mathrm{~mm}$ hammer-mill screen size and $400 \mathrm{t}$ annual capacity (Howarth et al., 2014).

Outputs from process are classified into three categories: fine fibre, fine powder, and coarse recyclates. Mass balances through the mechanical recycling process are shown in Figure 2. Fine fibre, fine powder and coarse recyclate fractions represent $24 \mathrm{wt} \%, 19 \mathrm{wt} \%$ and $57 \mathrm{wt} \%$ of outputs respectively (Palmer et al., 2010). Fine fibre, termed here "recycled carbon fibres"(rCF) can be reused as reinforcement material in new composites by replacing a certain proportion of raw fibre material; however, there are limits of proportion of $\mathrm{rCF}$ that can be used without resulting in a significant degradation of material properties (Pickering, 2006). Investigations into rCF use to replace the same volume virgin glass fibre (vGF) have shown mechanical properties are similar with composites using $100 \%$ vGF (Palmer et al., 2010): when produced with rCF, the flexural modulus of the composite material has slightly increased by $15 \%$ but mechanical flexural strength decreased by $14 \%$. Some literature claims $\mathrm{rCF}$ can be used to replace virgin carbon fibre (vCF) in direct injection moulding with nearly no degradation of mechanical properties (Takahashi et al., 2007). However, numerous other reports evaluating vCF replacement with rCF have shown significant degradation of the mechanical properties of rCF and the resulting composite material (Kouparitsas et al., 2002; Ogi et al., 2007).

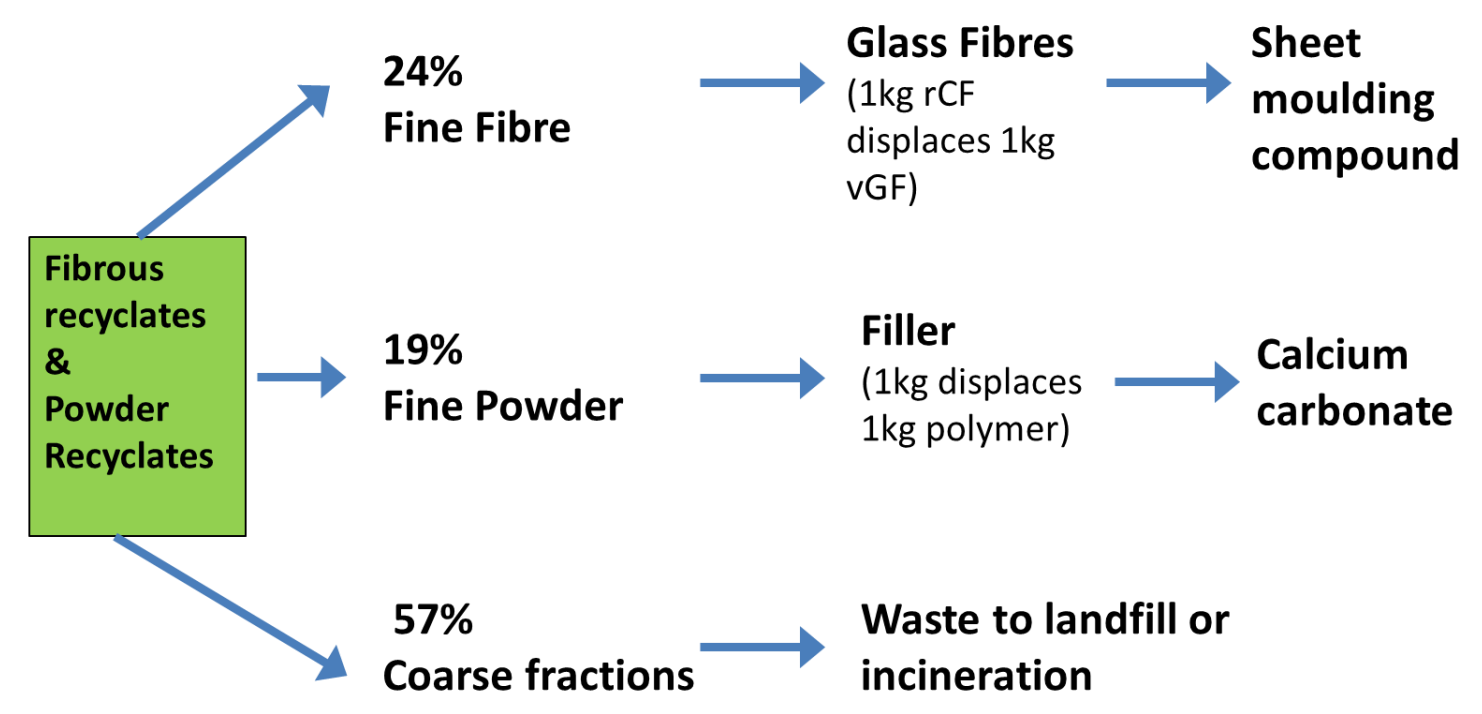

Figure 2. Material outputs of the mechanical recycling process. Based on (Palmer et al., 2010)

In the present study, fibrous $\mathrm{CF}$ recyclate ( $\mathrm{rCF}$ ) is assumed to displace glass fibres (GF) in composite materials at a ratio of 1:1 by weight, thereby avoiding the energy and GWP impacts of GF production. Based on the rCF yield from CFRP mechanical recycling, displacing $1 \mathrm{~kg}$ GF would require the input of $4.2 \mathrm{~kg}$ waste CFRP. Recovered $\mathrm{rCF}$ is assumed to be blended with virgin GF, unsaturated polyester resins and calcium carbonate filler to produce sheet moulding compound for subsequent component manufacture. A limited 20\% rCF is considered and expected to maintain the same material properties as sheet moulding compound containing only virgin GF (Palmer et al., 2010). Production of composite components from rCF-blended sheet moulding compound and their subsequent use are assumed to be identical to GF-based sheet moulding compound in terms of energy use, material inputs and cost; therefore, we do not include these activities within our models.

We consider a second hypothetical scenario where $\mathrm{rCF}$ is used in place of vCF in composite manufacture. This substitution is desirable for maximising revenue, due to the high value of vCF, and avoiding energy use and greenhouse gas emissions associated with vCF manufacture. However, the mechanical recycling process results in short fibres of degraded mechanical properties, which limits the viability of using rCF to replace new fibres. Following the approach of (Takahashi et al., 2007), we 
consider rCF displacing short vCF by considering a range "displacement factors", $\gamma_{C F}$, which represent the quantity of short $\mathrm{vCF}$ that can be displaced by $1 \mathrm{~kg} \mathrm{rCF}$ in a composite material: for example, a displacement factor of 0.5 would indicate that $1 \mathrm{~kg} \mathrm{rCF}$ can displace $0.5 \mathrm{~kg} \mathrm{vCF}$, with the resulting composite achieving the same mechanical properties as one produced entirely from vCF

Fine powder has well-established routes to replace raw filler material in polymer composites or aggregate materials (Conroy et al., 2006; Job, 2013). In this study, we assume the powder fraction is a suitable substitute for calcium carbonate filler in the cement kiln on a mass basis: $1 \mathrm{~kg}$ powder recyclate will displace $1 \mathrm{~kg}$ calcium carbonate, thereby avoiding energy consumption and greenhouse gas emissions associated with its production. The coarse fraction has technical difficulties to reuse in composites due to difficult bonding between coarse elements and matrix materials and is therefore treated as a waste product. We consider two scenarios for final treatment of the coarse fraction: landfilling and incineration with energy recovery, as detailed in sections 2.2 and 2.3, respectively.

\subsection{Life cycle cost analysis}

Costs associated with landfill and incineration are calculated as the sum of pre-treatment (shredding), transport, and tipping fees at landfill or incineration facility. Recent data on landfill tipping fees in the UK reveal a median cost of $£ 21 /$ tonne, excluding regulatory costs (Wrap, 2013). Landfill tax is applied to waste disposed of by landfill in the UK in order to encourage the use of more advanced waste treatment technologies that typically have higher tipping fees. Landfill tax results in an additional cost of landfilling CFRP waste of $£ 80 /$ tonne(EC, 2012). Tipping fees for incineration are reported as $£ 64 /$ tonne (WRAP, 2013). Incineration tipping fees are considered to represent the net cost of facility operation (capital, labour, maintenance) and revenues received from selling electricity and heat products; as such, these revenues are not accounted for separately in our model.

A cost model of CFRP mechanical recycling is developed, including capital and operational costs associated with the recycling facility construction and operation, in addition to initial CFRP pretreatment (dismantling, shredding), and transportation. Capital costs are estimated based on HedlundÅström (2005) and adjusted to a plant capacity of $400 \mathrm{t}$ CFRP/yr, and to account for equipment cost trends based on the CEPCI index (Lozowski, 2014). We assume a plant life of 20 years and a pre-tax equity rate of return of $15 \%$. Energy costs are quantified based on the UK industrial electricity price and fuel prices(DECC, 2014a, 2014b). Revenue from selling the CFRP recyclates (rCF and powder recyclates) is estimated assuming these return materials receive the same price as the reference products that they displace. The net cost of CFRP mechanical recycling is determined as the balance of all costs (waste pre-treatment, transport, and recycling process) and revenues. Key LCC outputs are converted to USD equivalents, assuming an exchange rate of $1.60 \mathrm{USD} / \mathrm{GBP}$.

Major costs and data sources are listed in Table 1, including: (1) CFRP waste pre-treatment cost including dismantling and shredding; (2) transportation to waste treatment site; (3) waste treatment processes cost; and (4) revenue from recyclate markets. All financial data has been converted to the 2014 UK pounds sterling. Transport costs are estimated including costs associated with time, mileage, and profit based on the method in RHA (2014). The diesel price is given as the 2014 annual average of the UK which is $£ 1.33$ litre (DECC, 2014b).

Markets for rCF are highly uncertain as recycling processes do not yet exist on a significant scale. As such, we consider the sensitivity of our results to potential value as a glass fibre substitute. We also consider higher market value scenario based on the use of $\mathrm{rCF}$ to displace vCF in composite applications. In this hypothetical scenario, we consider the market value of rCF to vary depending on its ability to displace $\mathrm{vCF}$ (as described in Section 2.4). We conservatively assume a maximum rCF value of $£ 12 / \mathrm{kg}$ (Carberry, 2008) where $\mathrm{rCF}$ is able to displace vCF on a $1: 1$ ratio $(1 \mathrm{~kg}$ rCF can displace $1 \mathrm{~kg} \mathrm{vCF}$ ). At lower displacement factors, the market value of $\mathrm{rCF}$ is assumed to proportionately decrease. For example, a displacement ratio of $20 \%$ indicates that $5 \mathrm{~kg} \mathrm{rCF}$ are required to displace $1 \mathrm{~kg}$ of $\mathrm{vCF}$ in a composite material application. In this scenario, our analysis 
assumes the rCF to have a market value of $£ 2.4 / \mathrm{kg}$, which is the maximum rCF value (£12) scaled by the displacement factor of $20 \%$. We discuss in detail impacts of rCF market value on financial viability in the context of vCF displacement in Section 3.4.2.

Table 1. Cost data summary of pre-treatment, transportation, waste treatment and revenue ${ }^{1}$

\begin{tabular}{llll}
\hline & Cost (£) & $\begin{array}{l}\text { Unit } \\
\text { basis }\end{array}$ & Source \\
\hline Dismantling & 1.38 & $/ \mathrm{kg}$ & Hedlund-Åström (2005) \\
Shredding & 0.035 & $/ \mathrm{kg}$ & Simic and Dimitrijevic (2012) \\
$\begin{array}{l}\text { Transportation } \\
\text { Landfilling process }\end{array}$ & 0.043 & $/ \mathrm{t}-\mathrm{km}$ & RHA (2014) \\
$\begin{array}{l}\text { With landfill tax } \\
\text { No landfill tax }\end{array}$ & 0.093 & $/ \mathrm{kg}$ & \\
Incineration process & 0.021 & $/ \mathrm{kg}$ & \\
$\begin{array}{l}\text { Recycling process/kg } \\
\text { (ME) }\end{array}$ & 0.064 & $/ \mathrm{kg}$ & Wrap (2013) \\
Virgin glass fibre & 0.27 & $/ \mathrm{kg}$ & Hedlund-Åström (2005) \\
$\begin{array}{l}\text { Filler (calcium } \\
\text { carbonate) }\end{array}$ & 0.68 & $/ \mathrm{kg}$ & Hischier (2014) \\
\hline
\end{tabular}

${ }^{1}$ All costs have been converted to 2014 UK pounds sterling

\subsection{Model Limitations}

The current study considers hypothetical CFRP treatment routes based on the best available data and assumptions representing possible landfilling, incineration, and recycling pathways. As a consequence, there are limitations to the accuracy of model that should be considered when interpreting results. Dismantling, transportation, and mechanical recycling are modelled based on publicly-available data regarding the cost, energy requirements, and output material properties and the authors' best estimates and do not reflect existing, physical facilities. We also face the challenge that markets for CFRP recyclate do not yet exist; as such, we have employed methods (detailed in Section $2.5)$ to estimate the market values for $\mathrm{rCF}$ and powder recyclate. To address these model limitations, we have considered a range of scenarios for $\mathrm{rCF}$ utilisation and, where appropriate, have evaluated the sensitivity of model results to uncertainty in key parameters.

\section{RESULTS AND DISCUSSIONS}

\subsection{Life cycle environmental impact results}

The GWP of the selected CFRP waste treatments is shown in Table 2. Landfilling produces minor GHG emissions of $24 \mathrm{kgCO}_{2}$ eq./t CFRP; due to the inert nature of CFRP waste, methane generation in landfill is not of concern. Incineration results in the greatest net GHG emissions, $2,011 \mathrm{~kg} \mathrm{CO}{ }_{2} \mathrm{eq} . / \mathrm{t}$ CFRP. Greenhouse gas emissions arise from the combustion process, during which the carbon content of CFRP is released to the atmosphere as $\mathrm{CO}_{2}\left(3,052 \mathrm{~kg} \mathrm{CO}_{2}\right.$ eq./t CFRP). Energy outputs from incineration are assumed to displace the average UK electricity grid mix and natural gas-fired heat generation; however, this GHG emissions credit (-1,041 $\mathrm{kg} \mathrm{CO}_{2}$ eq./t CFRP) is not sufficient to offset emissions associated with CFRP combustion. This is primarily due to the low efficiency of energy recovery from incineration (38\% combined electricity and heat generation efficiency) and the high carbon content in CFRP (more than 80wt\%). Efficiency improvement of waste incinerator has the potential to further reduce the emission intensity due to avoiding more raw energy product. Assuming higher conversion efficiencies of $25 \%$ (electricity generation) and $55 \%$ (heat generation), net GHG emissions can be reduced by half to $1,050 \mathrm{~kg} \mathrm{CO}$ eq./t CFRP. However, even in this high efficiency scenario where useful energy outputs are approximately doubled, avoided emissions associated with 
displacing UK grid electricity and natural gas-fired heat generation are insufficient to compensate for $\mathrm{CO}_{2}$ emissions arising from CFRP combustion.

Mechanical recycling with landfilling of the coarse recyclate fraction exhibits the lowest global warming potential among all the treatments considered. The mechanical recycling process is responsible for $85 \mathrm{~kg} \mathrm{CO}_{2}$ eq./t CFRP, with the electricity consumption for the milling process representing $77 \%$ of total emissions. The displacement of GF production, which is associated with $1,930 \mathrm{~kg} \mathrm{CO}{ }_{2}$ eq./t GF, results in a GHG emissions credit of $463 \mathrm{~kg} \mathrm{CO}_{2}$ eq./t CFRP. Thus, mechanical recycling of CFRP and displacement of GF results in a net global warming potential reduction of 378 $\mathrm{kg} \mathrm{CO} 2 \mathrm{eq} . / \mathrm{t}$ CFRP. In contrast, if the coarse recyclate fraction is incinerated, recycling will result in a net GHG emission increase of $750 \mathrm{~kg} \mathrm{CO} 2 \mathrm{eq} . / \mathrm{t}$ CFRP as nearly $60 \%$ of the incoming waste CFRP is incinerated.

As our models are based on hypothetical CFRP treatment routes, exact facility locations are not identified and as such there is significant uncertainty associated with transportation distances. However, varying transportation distance has only a minor impact on net GWP for all treatment processes considered in this study, particularly when compared to more greenhouse gas-intensive processes (e.g., CFRP incineration) and avoided emissions from product displacement (e.g., avoiding glass fibre production). Doubling transportation demands (100\% increase) would increase the net GWP associated with the Incineration, Recycling+Landfilling, and Recycling+Incineration pathways by $1 \%, 5 \%$, and $2 \%$, respectively. Only GWP results for landfilling are sensitive to transportation distance due to the relatively smaller magnitude of GWP emissions for this pathway.

Table 2. Global warming potential of CFRP waste treatments on landfilling, incineration and recycling to displace glass fibre.

\begin{tabular}{lcccc}
\hline & Landfilling & Incineration & $\begin{array}{c}\text { Recycling + } \\
\text { Landfilling }\end{array}$ & $\begin{array}{c}\text { Recycling+ } \\
\text { Incineration }\end{array}$ \\
\hline Dismantling & -- & $\mathrm{kg} \mathrm{CO}_{2}$ eq./t CFRP & & \\
Shredding & 11 & -- & 0 & 0 \\
Transportation & 8 & 11 & -- & -- \\
Waste treatment & 5 & 16 & 20 & 20 \\
Total GWP & 24 & 3,025 & 65 & 1,786 \\
Avoided & & 3,052 & 85 & 1,806 \\
emissions & -- & $-1,041$ & -463 & $-1,056$ \\
Net GWP & 24 & 2,011 & -378 & 750 \\
\hline
\end{tabular}

Net primary energy consumption is equal to cumulative energy demand of waste treatments minus the primary energy savings from recovery energy and recycled materials. Figure 3 shows primary energy demand and avoided energy use among landfilling, incineration and recycling. Landfilling consumes the least processing energy of $400 \mathrm{MJ} / \mathrm{t}$ CFRP, but does not avoid energy use and so results in a net increase in energy consumption. Incinerating 1 tonne CFRP waste directly recovers about 11,910 MJ/t CFRP secondary energy including electricity (4,030 MJ/t CFRP) and heat power (7,880 $\mathrm{MJ} / \mathrm{t}$ CFRP). Considering the current UK electricity mix and assumed $80 \%$ efficiency of heat generation from natural gas, CFRP incineration saves $23,750 \mathrm{MJ}$ primary energy consumption. The net primary energy demand by incineration is $-22,880 \mathrm{MJ} / \mathrm{t}$ CFRP after accounting for energy consumption associated with CFRP pre-treatment and transport, providing the greatest reduction in primary energy consumption of all end of life treatments investigated here.

Mechanical recycling activities require the input of 2,020 MJ/t CFRP, however recovered fibres and powder recyclate are assumed to avoid energy consumption associated with GF and filler materials, respectively. Assuming that the coarse recyclate fraction is landfilled, mechanical recycling can thus reduce primary energy consumption by $6,740 \mathrm{MJ} / \mathrm{t}$ CFRP, achieving a much smaller energy 
saving compared to incineration. However, if the remaining coarse recyclate fraction is incinerated with energy recovery, the net energy consumption of mechanical recycling improves to $-20,110 \mathrm{MJ} / \mathrm{t}$ CFRP - although this entails a significant increase in GHG emissions as detailed in Table 2. In all treatments, non-renewable energy dominates the total consumption, due to the UK's heavily dependency on non-renewable energy sources for transport fuels and electricity generation.

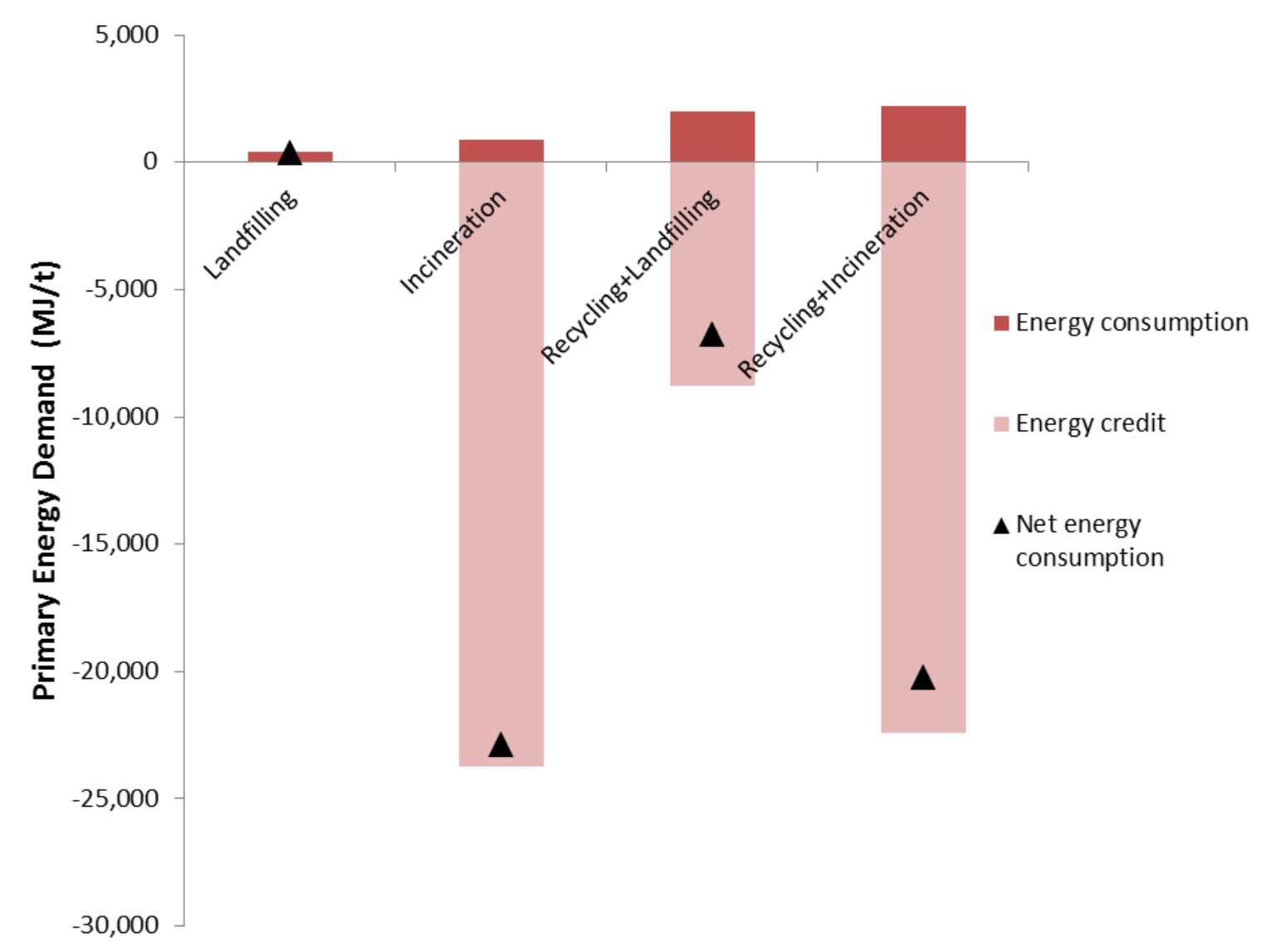

Figure 3. Net primary energy demands on landfilling, incineration and recycling.

Incineration and mechanical recycling can both be effective routes for avoiding landfill, as shown in Figure 4. Only 8\% of CFRP treated by incineration is disposed of in landfill, representing the ash content of this material. Mechanical recycling can similarly achieve a very low waste to landfill rate of $6 \%$, provided that the coarse recyclate fraction that is unsuitable for material uses is incinerated and only resulting ash is disposed of in landfill. If the coarse fraction is disposed of in landfill, mechanical recycling can still reduce the quantity of waste going to landfill by approximately $40 \%$. 


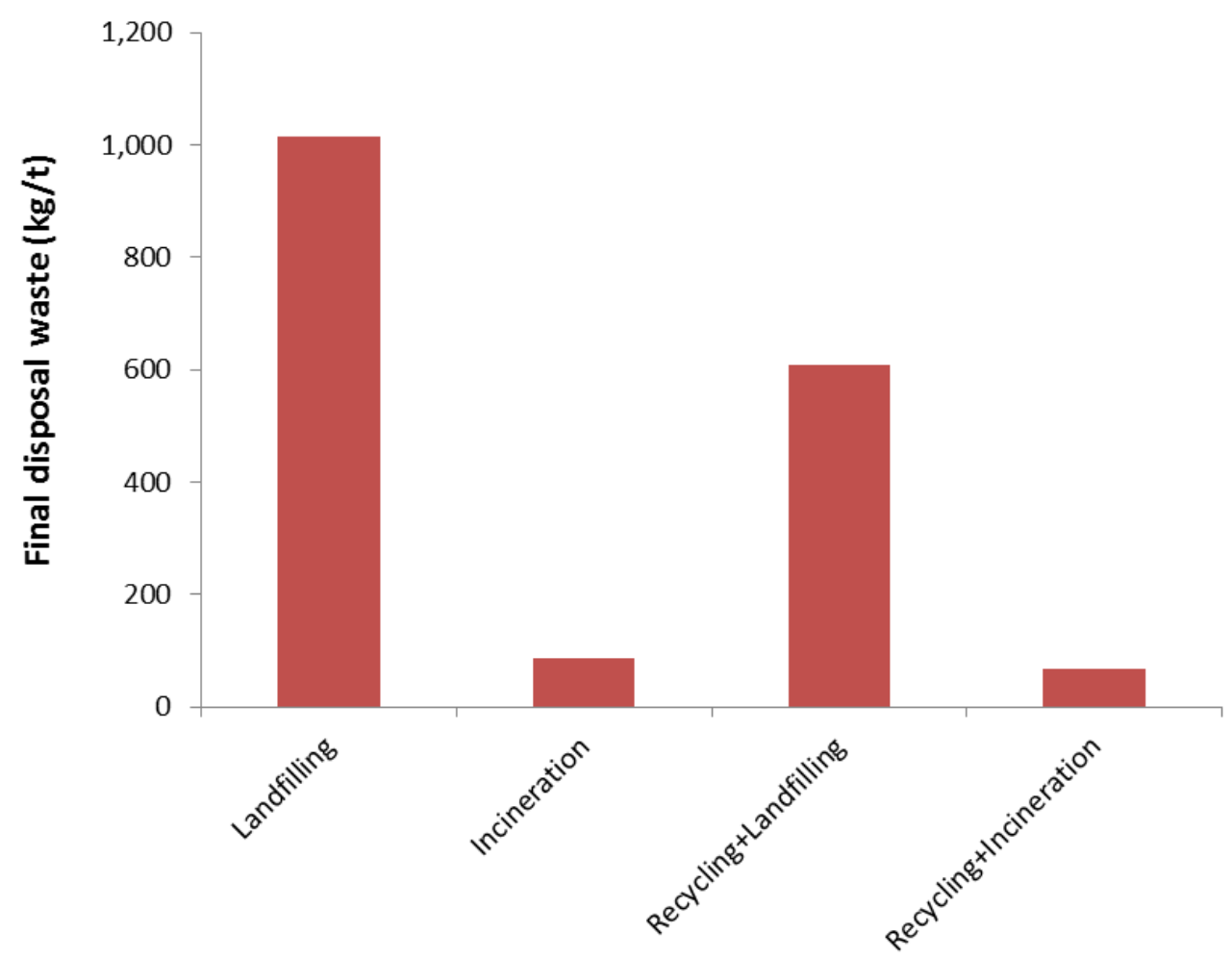

Figure 4. CFRP waste treatments on final disposal waste.

\subsection{Life cycle cost analysis results}

The LCC cost analysis is performed in parallel to the LCA to assess trade-offs between environmental and financial performance. Figure 5 shows the net costs of all waste treatments. Shredding is a significant cost for both landfilling and incineration routes, while transportation costs constitute a small fraction of total costs for all treatment routes. Landfilling is the lowest cost waste treatment route (£60/t CFRP ( $\$ 100 /$ t CFRP)); however, this cost increases to £132/t CFRP (\$220/t CFRP) when the UK landfill tax is taken into account. As a result, landfilling of CFRP waste becomes more costly than incineration (£115/t CFRP(\$190/t CFRP)), suggesting that landfill tax could shift waste CFRP from landfilling to incineration. While landfill tax is therefore seen to be effective in diverting CFRP wastes from landfill, this has mixed environmental consequences as detailed in Section 3.1. These results are dependent on assumptions regarding transport distances. If transport distance to the incineration facility is substantially increased (600 km vs $200 \mathrm{~km})$, landfilling is found to be the lowest cost disposal route.

Compared with conventional waste treatment routes, mechanical recycling of CFRP waste and use of $\mathrm{rCF}$ to displace GF is a far higher net cost, exceeding $£ 2,500 / \mathrm{t}$ CFRP $(\$ 4,100 / \mathrm{t}$ CFRP). For such a process to be viable, an equivalent gate fee would need to be charged for the disposal of CFRP waste. The fate of the coarse recyclate fraction (landfilled or incinerated) is inconsequential to the financial analysis, and so only a single set of results is shown here. Pre-treatment and the recycling process contribute approximately equal shares to total mechanical recycling cost. Prior to the main recycling process, CFRP components must be manually dismantled from the vehicle to separate CFRP components from other materials, with an estimated cost of $£ 1,390 / t$ CFRP $(\$ 2,300 /$ t CFRP). Costs associated with the recycling process total $£ 1,320 / \mathrm{t}$ CFRP $(\$ 2,200 / \mathrm{t}$ CFRP), including capital, labour, and replacement of worn hammer mill knives. Transportation costs represent less than $1 \%$ of total costs associated with the recycling process. Revenue from $\mathrm{rCF}$ displacing $\mathrm{GF}$ and powder recyclate displacing polymer filler (calcium carbonate) total approximately £200/t CFRP ( $\$ 330 / \mathrm{t} \mathrm{CFRP),} \mathrm{81 \%}$ 
of which is derived from rCF sales. The net cost of mechanical recycling is thus insensitive to likely recyclate revenues. Doubling the value for rCF displacing GF to $£ 1.40 / \mathrm{kg}$ still results in net recycling costs in excess of $£ 2,300 / \mathrm{t} \mathrm{CFRP.} \mathrm{It} \mathrm{is} \mathrm{only} \mathrm{at} \mathrm{a} \mathrm{much} \mathrm{higher} \mathrm{rCF} \mathrm{value}(£ 11 / \mathrm{kg})$ that net zero recycling costs can be achieved. Where CFRP waste is from manufacturing processes rather than an end of life vehicle component, costs associated with dismantling could be avoided. This would significantly reduce the cost of recycling to $£ 1,100 / t$ CFRP. However, this cost is still an order of magnitude more expensive than conventional landfill and incineration treatment routes. The low revenue from $\mathrm{rCF}$ is due primarily to two factors: its use displacing a low cost material; and the low recovery rate of rCF from CFRP ( 40\% of CFRP fibre content). These results imply the improvement fibre recovery rate, more valuable displacement and lower dismantling fee has the potential to reduce the cost.

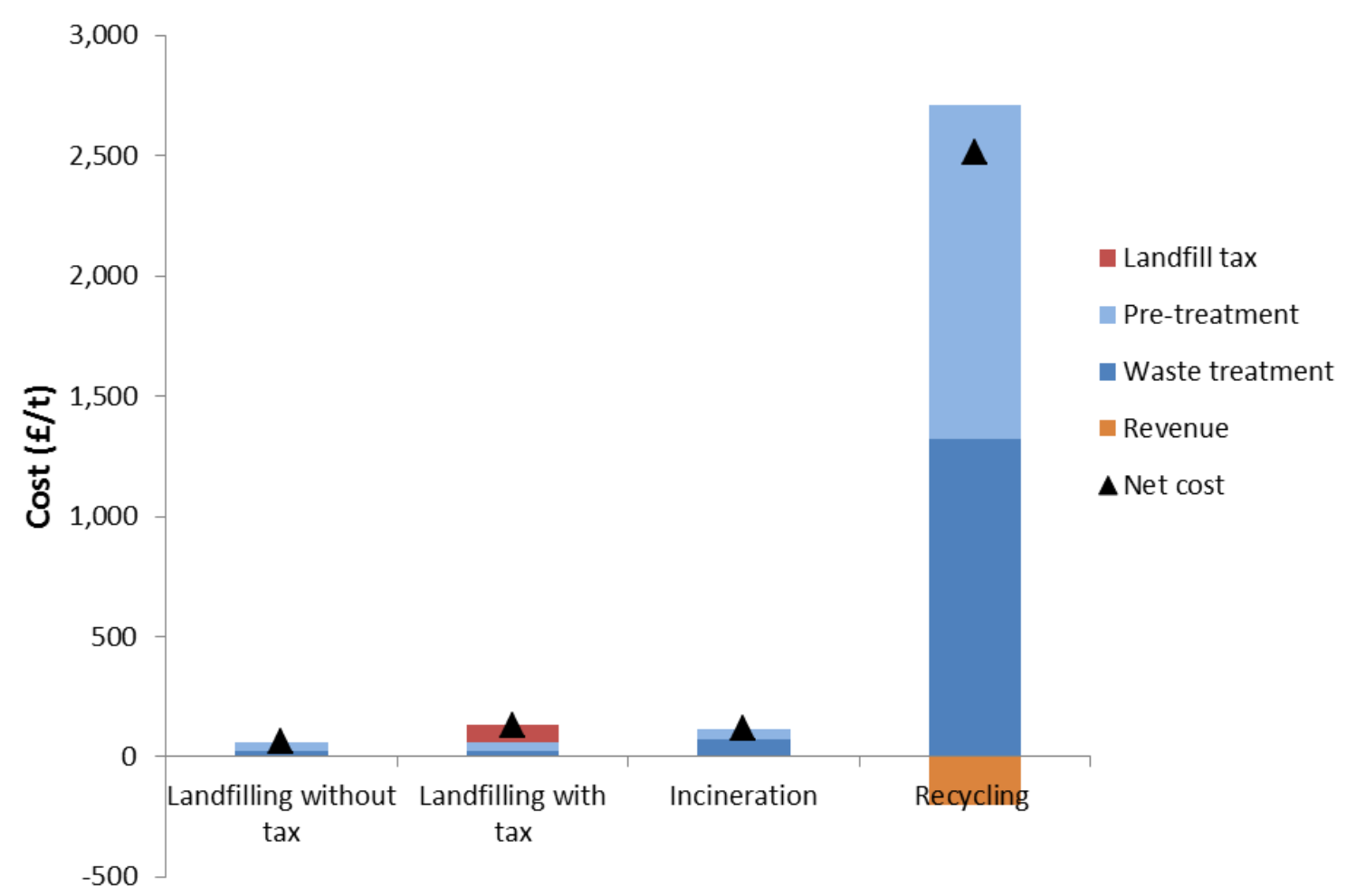

Figure 5. Cost comparison on landfilling with tax, landfilling without tax, incineration and mechanical recycling with glass fibre substitution

\subsection{Automotive CFRP and compliance with EU End of Life Vehicle Directive}

Where CFRP components are used in automotive applications, the EU End of Life Vehicles Directive is of particular relevance to waste management decisions. In 2015, targets for material recovery (including energy recovery) and recycling increased to $95 \%$ and $85 \%$, respectively (EC, 2000). Future lightweight light duty vehicles could be expected to contain $30 \%$ plastics by weight, including $15 \%$ CFRP, compared to only $11 \%$ plastics by weight in conventional vehicles (ANL, 2014). Based on this composition, it is likely that some CFRP will have to be recycled and energy recovered from the majority of CFRP and other polymeric materials to satisfy the End of Life Vehicle Directive. Figure 6 considers a mix of CFRP treatments to meet a set recycling rate and to minimise cost. As incineration is the lowest cost option, all CFRP wastes are assumed to be incinerated if there is no requirement to recycling any CFRP materials. As the target CFRP recycling rate increases, a greater 
portion of CFRP waste is diverted to mechanical recycling. As a consequence, costs rapidly increase and greatly exceed that of conventional disposal routes: total CFRP disposal costs are doubled at a recycling rate of only 5\%. These results suggest a risk to compliance with the End of Life Vehicles Directive unless lower cost CFRP recycling strategies become available. Implications of these results are discussed further in Section 3.5.

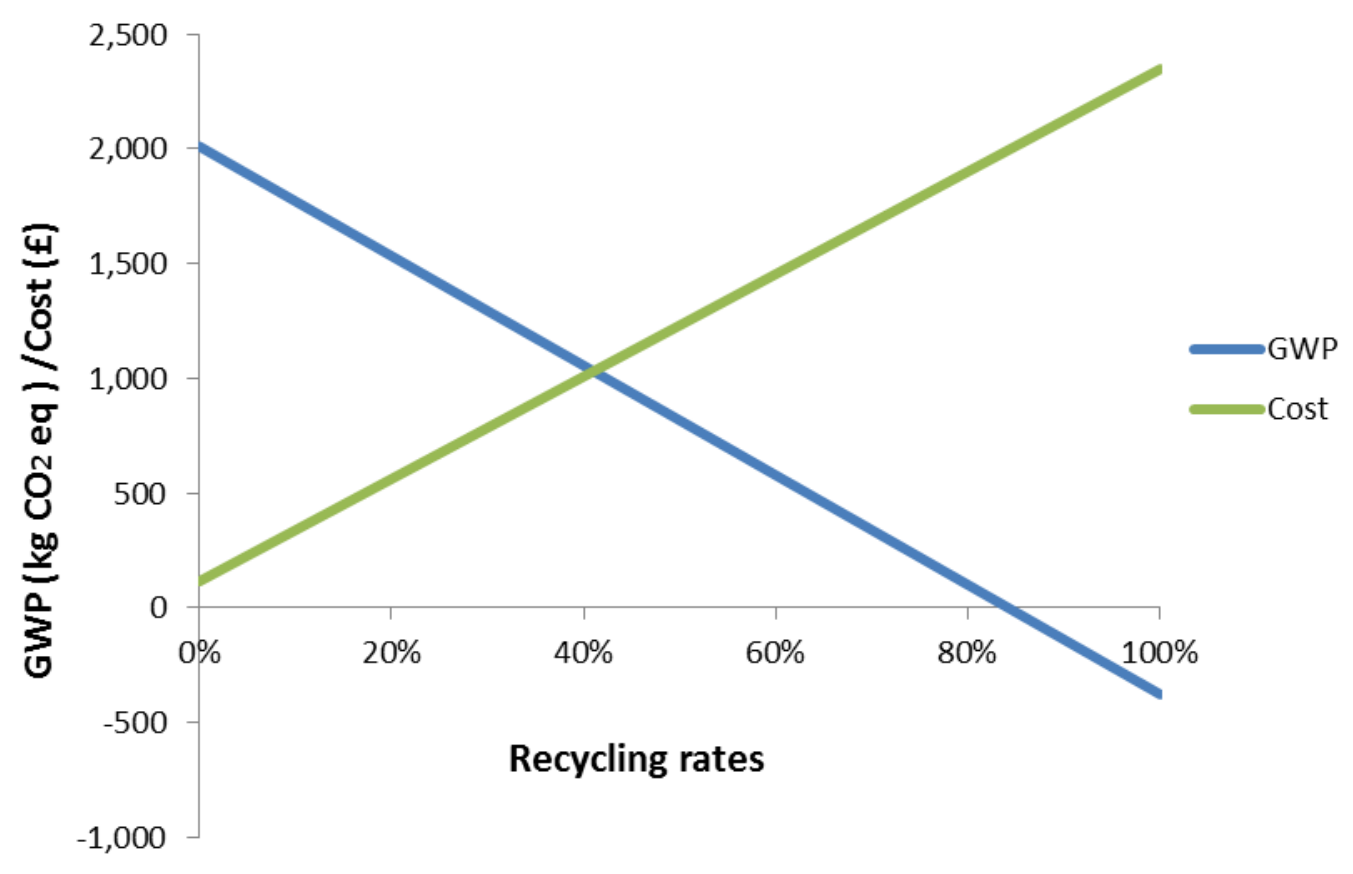

Figure 6. Cost and GWP impact of meeting CFRP recycling rate targets to comply with EU End of Life Vehicle Directive.

\subsection{Sensitivity analysis}

In this section, we consider the impact of key parameters on the environmental and financial performance of mechanical recycling of CFRP wastes. These analyses are conducted both to understand the impacts of uncertainty and variability in these parameters, but also to understand the potential of advanced recycling techniques that may be capable of recovering a greater fraction of $\mathrm{CF}$ contained in waste CFRP and displacing higher value vCF.

\subsubsection{Improving fiber recovery rates}

Increasing $\mathrm{rCF}$ recovery rates can improve environmental and financial performance of the mechanical recycling route: in the base case, only $40 \%$ of CF present in CFRP waste is assumed to be recoverable as $\mathrm{rCF}$. Considering higher rCF recovery rates is hypothetical: this would not be achievable with mechanical recycling; however, advanced thermal recycling technologies, such as fluidised bed, could be expected to approach $100 \%$ rCF recovery (Pimenta \& Pinho, 2011). If complete rCF recovery is achieved (e.g., 100\% recovery rate), avoided GHG emissions associated with CFRP recycling more than double $\left(-1,100 \mathrm{~kg} \mathrm{CO}_{2}\right.$ eq./t CFRP) compared to the base case. In contrast, the cost of CFRP mechanical recycling is not significantly impacted by the rCF recovery rate. Increasing the recovery rate from $40 \%$ to $100 \%$ is associated with a net cost reduction of only $11 \%$ (from $£ 2,500 /$ CFRP ( $\$ 4,100 /$ t CFRP) to $£ 2,300 / t$ CFRP( $\$ 3,700 / t$ CFRP)), with waste treatment costs remaining an order of magnitude greater than conventional waste treatment routes. The high cost of mechanical recycling, even at high $\mathrm{rCF}$ recovery rates, is due to the low market value of $\mathrm{rCF}$ when 
displacing GF. Therefore, to achieve a cost-effective recycling route, it is clear that rCF must displace higher value products.

\subsubsection{Displacing carbon fibre}

Using rCF to displace vCF could greatly improve the environmental and financial performance of CFRP recycling compared to GF displacement. Achieving a high displacement ratio is very hypothetical and not likely to be achieved with mechanically recycled $\mathrm{rCF}$, due to the degradation of fibre mechanical properties, the presence of impurities mixed with the $\mathrm{rCF}$ stream, and reduced/inconsistent fibre lengths. However, such displacements may be feasible with thermal recycling processes (pyrolysis, fluidised bed). Figure 7 shows the net GWP and costs associated with CFRP recycling where $\mathrm{rCF}$ is used to displace $\mathrm{VCF}$ and residual materials are disposed of in landfill and for two rCF recovery rates $(40 \%, 100 \%$ of fibre contained in waste CFRP). Due to the GHGintensity of $\mathrm{vCF}$ manufacture, a net reduction in global warming potential could be achieved at very low displacement factors $(<10 \%)$ even when only $40 \%$ of available fibres are recovered. Financial viability is also improved if $\mathrm{vCF}$ can be displaced, but the fibre recovery rate remains important. If only $40 \%$ of fibres are recovered, CFRP recycling will remain a net cost even at high displacement ratios. However, if all fibres can be recovered, a displacement factor of $40 \%$ is sufficient to achieve net zero cost of recycling. While we do not suggest that such performance is feasible with mechanical recycling, this analysis indicates the potential benefits that could potentially be achieved with more advanced thermal recycling processes.

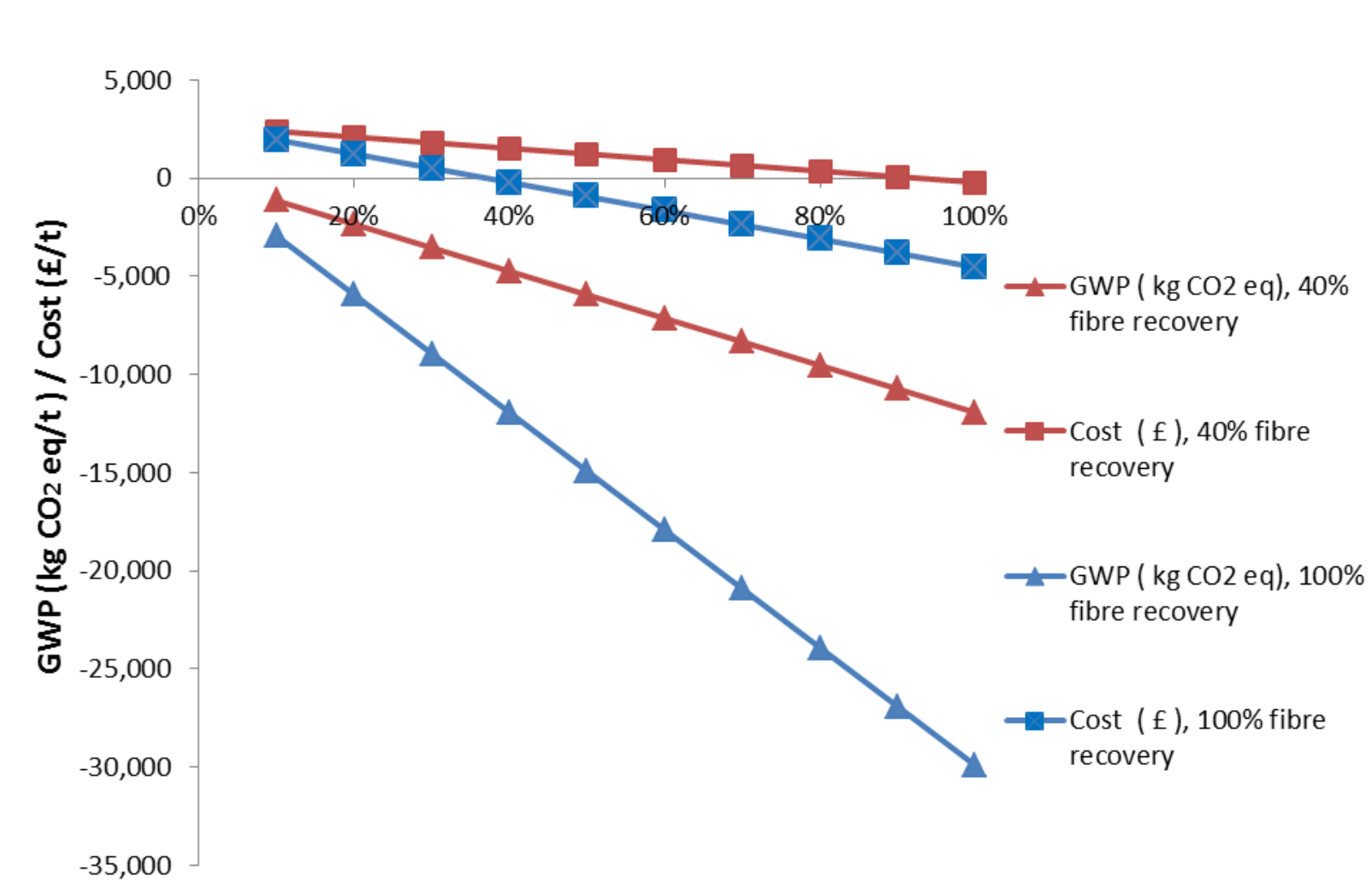

\section{Displacement ratio $\mathrm{rCF} / \mathrm{vCF}$}

Figure 7. Net global warming potential and cost of CFRP recycling with displacement of virgin carbon fibres. 


\subsection{Discussion}

Mechanical recycling is a technologically mature method to reclaim materials from waste in large quantities. Applied to CFRP waste treatment, mechanical recycling is capable of recovering a significant portion of CF from waste in addition to powder recyclate for polymer filler applications and residual materials that are potentially suitable for energy recovery, thus avoiding landfill. Overall, CFRP mechanical recycling exhibits low energy consumption and associated greenhouse gas emissions and can thus improve environmental performance relative to conventional disposal methods (landfilling, incineration) while contributing to waste recycling and recovery objectives.

Environmental benefits associated with mechanical CFRP recycling are largely driven by the fibre recovery rate, potential markets for $\mathrm{rCF}$, and fate of residual materials (landfill, incineration).

Despite potential environmental benefits, our results suggest that CFRP mechanical recycling is unlikely to be financially viable due to the low fibre recovery rate and degradation of the mechanical properties of rCF. As a consequence, revenues from low-value recyclate end uses (e.g., glass fibre displacement, polymer filler) cannot compensate for the cost of vehicle dismantling, transport, and waste recovery processes required for $\mathrm{rCF}$ recovery, even under optimistic assumptions for recycling costs and market value of rCF. It is apparent that CFRP recycling will only be financially viable if fibre recovery rates near $100 \%$ can be achieved and if rCF can be input to higher value applications. Improving rCF properties - in particular, avoiding mechanical property degradation - is essential for the latter factor to be realised.

Among conventional waste treatment routes, our results are consistent with prior studies investigating municipal solid waste in finding that regulatory fees drive incineration as a lower cost option than landfilling (e.g., Reich, 2005). However, whereas incineration of municipal solid waste can achieve net greenhouse gas emissions reductions relative to landfilling, combustion of composites with inherently minimal decomposition potential is a significant net emissions source. This analysis thus highlights trade-offs between these four metrics (cost, GWP, energy use, landfill waste generation) that arise as a result of current waste treatment policy. Results presented here and elsewhere (e.g., Eriksson et al., 2005) indicate that waste treatment decisions should be informed by the source of waste, its degradability potential, and its carbon content in order to minimise life cycle global warming potential.

Policy interventions and financial incentives have a successful record in driving desired waste treatment behaviour; for example, the UK landfill tax has been highly successful in diverting waste from landfill (Talbot, 2014). However, it is unlikely that such financial incentives would be appropriate for encouraging mechanical recycling of CFRP wastes due to the high level of policy support required, estimated in the present study as approximately $£ 2,500 / t$ CFRP (vs. the current $£ 80 / t$ landfill tax). Further, this high cost cannot be justified by potential environmental benefits. If CFRP recycling prevents incineration of this waste material (the highest GWP pathway evaluated), the cost associated with mitigating GHG emissions by recycling is estimated to be $£ 1,100 / \mathrm{t} \mathrm{CO}_{2} \mathrm{eq}$ when recovered fibres are only suitable as a glass fibre substitute. This cost two orders of magnitude greater than the social cost of carbon emissions ( $£ 10$ to $£ 38 / \mathrm{tCO}_{2}$ eq.) (DECC, 2013) and exceeds costs found in previous studies investigating plastics recovery from end of life vehicles (e.g., Duval and MacLean, 2007).

The high cost of mechanical recycling poses a particular risk to automotive CFRP applications compliance with the EU End of Life Vehicles Directive. Gerrard and Kandlikar (2007) arrived at a similar conclusion, noting that while ELV legislation has contributed to greater consideration of recyclability in the design process, it may also negatively impact the use of novel materials which lack a viable recycling route. To mitigate this risk, cost-effective CFRP recycling routes must be identified. Other treatment routes not considered in this study may be capable of contributing to waste treatment objectives in more cost effective ways. For example, cement kiln firing is proposed by European Composites Industry Association as a route to recover approximately 2/3 of composite materials for 
cement, with the remainder recovered for energy (EuCIA, 2009). However, kiln co-firing would still face the high cost of dismantling and requires further investigation to assess the life cycle environmental and financial performance. The cost of CFRP dismantling is thus identified as a common barrier to financially viable treatment of automotive CFRP wastes. Our results indicate that dismantling accounts for approximately half of total mechanical recycling costs. Other researchers have identified this same issue, for example in investigating end of life car bumper recycling (Tian et al., 2015). Design for disassembly approaches could help to significantly reduce this cost (Mayyas et al., 2012). Further, advanced recycling processes, including pyrolysis (Meyer et al., 2009) and fluidised bed (Pickering, 2012) technologies, show potential as viable recycling routes as they can achieve near-100\% fibre recovery while largely maintaining the mechanical properties of recovered CF. Our sensitivity analysis demonstrates the potential viability of processes that can achieve high fibre recovery rates and high value applications (e.g., vCF displacement). However, further investigation of the life cycle cost and environmental impacts of these processes is required to understand trade-offs between multiple objectives and to ensure that net benefits can be achieved.

\section{CONCLUSIONS}

This work investigates the environmental and financial performance of CFRP waste treatment by landfilling, incineration and mechanical recycling to identify trade-offs between these three waste treatment routes. Landfilling is found to have modest environmental impacts; however, this treatment route is in opposition to policy initiatives including landfill diversion and, in the case of automotive components, recovery of materials from end of life vehicles. Incineration can comply as a recovery method under the End of Life Vehicle Directive and is able to greatly reduce primary energy consumption by generating electricity and heat from waste. However, this treatment route is found to be a potentially significant GHG emissions source, due to the release of constituent carbon during combustion. Our results show that landfill tax may shift CFRP waste from landfill to incineration with resulting impacts on GHG emissions.

Mechanical recycling is found to be able to reduce GHG emissions, primary energy use, and landfill waste generation relative to landfilling. However, the comparatively high costs of mechanical recycling and low revenues when $\mathrm{rCF}$ is used to displace glass fibres are substantial barriers to financial viability of the process. Targeting higher value uses for $\mathrm{rCF}$, including the displacement of $\mathrm{vCF}$, is key to achieving an environmentally and financially viable process. Revenues could thus be increased by targeting higher value rCF markets, while superior environmental performance could be achieved by displacing more energy-intensive materials. Degradation of $\mathrm{rCF}$ properties during the mechanical recycling process, however, is likely to constrain rCF use to low value applications. While there are therefore few opportunities to improve the performance of mechanical recycling techniques, emerging recycling technologies such as fluidised bed and pyrolysis-based processes are very promising in these regards. However, comprehensive assessment of advanced CFRP recycling processes will be required to understand trade-offs associated with energy requirements and substantially greater capital investment compared with mechanical recycling, and to determine the contribution of these factors to life cycle environmental impacts and costs.

\section{ACKNOWLEDGEMENTS}

The project is supported by the Low Carbon Manufacturing of Automotive Products Innovation Team Project of Ningbo (2011B81006) 


\section{REFERENCES}

Alonso, Juan C, Dose, Julia, Fleischer, Günter, Geraghty, Kate, Greif, André, Rodrigo, Julio, $\&$ Schmidt, Wulf-Peter. (2007). Electrical and electronic components in the automotive sector: Economic and environmental assessment. The International Journal of Life Cycle Assessment, 12(5), 328-335.

ANL. (2014). GREET website. Retrieved May, 2015, from https://greet.es.anl.gov/

Chen, Zhiguo, Chen, Dingjiang, Wang, Tao, \& Hu, Shanying. (2015). Policies on end-of-life passenger cars in China: dynamic modeling and cost-benefit analysis. Journal of Cleaner Production, 108, 1140-1148.

Ciacci, Luca, Morselli, Luciano, Passarini, Fabrizio, Santini, Alessandro, \& Vassura, Ivano. (2010). A comparison among different automotive shredder residue treatment processes. The International Journal of Life Cycle Assessment, 15(9), 896-906.

Conroy, Amanda, Halliwell, Sue, \& Reynolds, Tim. (2006). Composite recycling in the construction industry. Composites Part A: Applied Science and Manufacturing, 37(8), 1216-1222.

Das, Sujit. (2011). Life cycle assessment of carbon fiber-reinforced polymer composites. The International Journal of Life Cycle Assessment, 16(3), 268-282.

DECC. (2014a). Quarterly energy prices. Retrieved Feb 12, 2015, from https://www.gov.uk/government/uploads/system/uploads/attachment_data/file/368077 lqep_Sep_14.pdf

DECC. (2014b). Road fuel and other petroleum product price statistics. Retrieved Feb 12, 2015, from https://www.gov.uk/government/collections/road-fuel-and-otherpetroleum-product-prices

DEFRA. (2013). Incineration of municipal solid waste. Retrieved Feb 12, 2015, from https://www.gov.uk/government/uploads/system/uploads/attachment_data/file/221036 /pb13889-incineration-municipal-waste.pdf

Duflou, JR, De Moor, Jozef, Verpoest, Ignace, \& Dewulf, Wim. (2009). Environmental impact analysis of composite use in car manufacturing. CIRP Annals-Manufacturing Technology, 58(1), 9-12.

Duval, Don, \& MacLean, Heather L. (2007). The role of product information in automotive plastics recycling: a financial and life cycle assessment. Journal of Cleaner Production, 15(11), 1158-1168.

EuCIA. (2009). Thermosets Composites are compliant with EU Directive Position Paper on Recycling of Thermosetting Composite Parts in the Automotive Industry

European_Commission. (2000). Directive 2000/53/EC of the European Parliament and of the Council of 18 September 2000 on end-of-life vehicles. Official Journal of the European Communities, L, 269, 34-269. 
European_Commission. (2006). Reference document on the best available techniques for waste incineration. Retrieved Feb 12, 2015, from

http://eippcb.jrc.ec.europa.eu/reference/BREF/wi_bref_0806.pdf

European_Commission. (2012). Use of Economic Instruments and Waste Management Performances. Retrieved Feb 12, 2015, from http://ec.europa.eu/environment/waste/pdf/final_report_10042012.pdf

Fabrycky, Wolter J, \& Blanchard, Benjamin S. (1991). Life-cycle cost and economic analysis: Prentice Hall.

Gerrard, Jason, \& Kandlikar, Milind. (2007). Is European end-of-life vehicle legislation living up to expectations? Assessing the impact of the ELV Directive on 'green'innovation and vehicle recovery. Journal of Cleaner Production, 15(1), 17-27.

Graedel, TE, Allwood, J, Birat, JP, Reck, BK, Sibley, SF, Sonnemann, G, . . Hagelüken, C. (2011). UNEP (2011) Recycling Rates of Metals-A Status Report. A Report of the Working Group on the Global Metal Flows to the International Resource Panel, United Nations Environment Programme.

Hedlund-Åström, Anna. (2005). Model for end of life treatment of polymer composite materials. (Doctoral thesis), Royal Institute of Technology.

Herczeg, M, Skovgaard, M, Zoboli, R, \& Mazzanti, M. (2009). Diverting waste from landfill. Effectiveness of waste management policies in the European Union. European Environment Agency Report(7).

Hischier, R. (2014). Ecoinvent data. The life cycle inventory data version. Swiss Centre for Life Cycle Inventories, St. Gallen.

Howarth, Jack, Mareddy, Sada SR, \& Mativenga, Paul T. (2014). Energy intensity and environmental analysis of mechanical recycling of carbon fibre composite. Journal of Cleaner Production, 81, 46-50.

ISO, EN. (2006). 14040: 2006. Environmental management-Life cycle assessment-Principles and framework.

Job, Stella. (2013). Recycling glass fibre reinforced composites-history and progress. Reinforced Plastics, 57(5), 19-23.

Kim, Junbeum, Hwang, Yongwoo, \& Park, Kwangho. (2009). An assessment of the recycling potential of materials basedon environmental and economic factors; case study in South Korea. Journal of Cleaner Production, 17(14), 1264-1271.

Kouparitsas, CE, Kartalis, CN, Varelidis, PC, Tsenoglou, CJ, \& Papaspyrides, CD. (2002). Recycling of the fibrous fraction of reinforced thermoset composites. Polymer composites, 23(4), 682-689.

Lozowski, D. (2014). Chemical engineering plant cost index (CEPCI). Chem Eng, 119, 84.

MacLeay, Iain. (2014). Digest of United Kingdom energy statistics 2014: The Stationery Office. 
Mayyas, Ahmad, Qattawi, Ala, Omar, Mohammed, \& Shan, Dongri. (2012). Design for sustainability in automotive industry: A comprehensive review. Renewable and Sustainable Energy Reviews, 16(4), 1845-1862.

Meyer, LO, Schulte, Karl, \& Grove-Nielsen, E. (2009). CFRP-recycling following a pyrolysis route: process optimization and potentials. Journal of composite materials.

Ogi, Keiji, Nishikawa, Takashi, Okano, Yasutaka, \& Taketa, Ichiro. (2007). Mechanical properties of ABS resin reinforced with recycled CFRP. Advanced Composite Materials, 16(2), 181-194.

Oliveux, Géraldine, Dandy, Luke O, \& Leeke, Gary A. (2015). Current status of recycling of fibre reinforced polymers: Review of technologies, reuse and resulting properties. Progress in Materials Science, 72, 61-99.

Palmer, J, Savage, L, Ghita, OR, \& Evans, KE. (2010). Sheet moulding compound (SMC) from carbon fibre recyclate. Composites Part A: Applied Science and Manufacturing, $41(9), 1232-1237$.

Palmer, James Alexander Thomas, Ken, Evans, \& Oana, Ghita. (2009). Mechanical recycling of automotive composites for use as reinforcement in thermoset composites.

Passarini, Fabrizio, Ciacci, Luca, Santini, Alessandro, Vassura, Ivano, \& Morselli, Luciano. (2012). Auto shredder residue LCA: implications of ASR composition evolution. Journal of Cleaner Production, 23(1), 28-36.

Pickering, SJ. (2006). Recycling technologies for thermoset composite materials-current status. Composites Part A: Applied Science and Manufacturing, 37(8), 1206-1215.

Pickering, SJ. (2012). Recycling Thermoset Composite Materials. Wiley Encyclopedia of Composites.

Pimenta, Soraia, \& Pinho, Silvestre T. (2011). Recycling carbon fibre reinforced polymers for structural applications: Technology review and market outlook. Waste management, 31(2), 378-392.

RHA. (2014). RHA Cost Tables 2014: RHA Weybridge.

Sakai, Shin-ichi, Yoshida, Hideto, Hiratsuka, Jiro, Vandecasteele, Carlo, Kohlmeyer, Regina, Rotter, Vera Susanne, . . . Li, Jinhui. (2014). An international comparative study of end-of-life vehicle (ELV) recycling systems. Journal of Material Cycles and Waste Management, 16(1), 1-20.

Santini, Alessandro, Morselli, Luciano, Passarini, Fabrizio, Vassura, Ivano, Di Carlo, Salvatore, \& Bonino, Francesco. (2011). End-of-Life Vehicles management: Italian material and energy recovery efficiency. Waste management, 31(3), 489-494.

Shapiro, Sara, \& Johannessen, Maja. (2015). Promoting recycling of plastics from end-of-life vehicles. 
Simões, Carla L, Pinto, Lígia M Costa, \& Bernardo, CA. (2013). Environmental and economic assessment of a road safety product made with virgin and recycled HDPE: a comparative study. Journal of environmental management, 114, 209-215.

Simic, Vladimir, \& Dimitrijevic, Branka. (2012). Production planning for vehicle recycling factories in the EU legislative and global business environments. Resources, Conservation and Recycling, 60, 78-88.

Stocker, TF, Qin, D, Plattner, GK, Tignor, M, Allen, SK, Boschung, J, . . Midgley, BM. (2013). IPCC, 2013: climate change 2013: the physical science basis. Contribution of working group I to the fifth assessment report of the intergovernmental panel on climate change.

Takahashi, Jun, Matsutsuka, Nobukuni, Okazumi, Tetsuya, Uzawa, Kiyoshi, Ohsawa, Isamu, Yamaguchi, Koji, \& Kitano, Akihiko. (2007). Mechanical properties of recycled CFRP by injection molding method. ICCM-16, Japan Society for Composite Materials, Kyoto, Japan.

Tian, Jin, Ni, Feijian, \& Chen, Ming. (2015). Application of pyrolysis in dealing with end-oflife vehicular products: a case study on car bumpers. Journal of Cleaner Production, $108,1177-1183$.

Timmis, Andrew J, Hodzic, Alma, Koh, Lenny, Bonner, Michael, Soutis, Constantinos, Schäfer, Andreas W, \& Dray, Lynnette. (2015). Environmental impact assessment of aviation emission reduction through the implementation of composite materials. The International Journal of Life Cycle Assessment, 20(2), 233-243.

Witik, Robert A, Payet, Jérôme, Michaud, Véronique, Ludwig, Christian, \& Månson, JanAnders E. (2011). Assessing the life cycle costs and environmental performance of lightweight materials in automobile applications. Composites Part A: Applied Science and Manufacturing, 42(11), 1694-1709.

Witik, Robert A, Teuscher, Remy, Michaud, Véronique, Ludwig, Christian, \& Månson, JanAnders E. (2013). Carbon fibre reinforced composite waste: an environmental assessment of recycling, energy recovery and landfilling. Composites Part A: Applied Science and Manufacturing, 49, 89-99.

Witten, Elmar, Kraus, Thomas, \& Kühnel, Michael. (2014). Composites Market Report 2014 Market developments, trends, challenges and opportunities-The Global CRP Market.

Wrap. (2013). Gate Fees Report 2013.

Zhao, Wei, Huppes, Gjalt, \& van der Voet, Ester. (2011). Eco-efficiency for greenhouse gas emissions mitigation of municipal solid waste management: A case study of Tianjin, China. Waste management, 31(6), 1407-1415. 
